\title{
Optimization of Mechanical and Wear Properties of Functionally Graded Al6061/SiC Nanocomposites Produced by Friction Stir Processing (FSP)
}

\author{
M. Saadatmand · J. Aghazadeh Mohandesi
}

Received: 7 July 2014/Revised: 24 November 2014/Published online: 19 March 2015

(C) The Chinese Society for Metals and Springer-Verlag Berlin Heidelberg 2015

\begin{abstract}
The objective of present work is to apply the friction stir processing (FSP) to fabricate functionally graded $\mathrm{SiC}$ particulate reinforced Al6061 composite and investigate the effect of $\mathrm{SiC}$ particle mass fraction distribution on the mechanical properties and wear behavior of A16061/SiC composite. Regarding the obtained results in this work, with increasing $\mathrm{SiC}$ mass fraction, elongation decreased, but hardness enhanced. However, the optimized functionally graded composite with the highest tensile strength and wear resistance was achieved for composite with $10 \mathrm{wt} \%$ surface SiC. Also, the results showed that wear resistance and tensile strength decreased for composite with $13 \mathrm{wt} \%$ surface $\mathrm{SiC}$, due to reinforcement particle clustering depending on high $\mathrm{SiC}$ mass fraction.
\end{abstract}

KEY WORDS: Functionally graded composite; Wear; Mechanical properties; Friction stir processing (FSP)

\section{Introduction}

Friction stir processing (FSP) technique [1] has been applied for producing $\mathrm{Mg}$ - [2] and Al-based nanocomposites [3-5]. In contrast to powder metallurgy and liquid metallurgy, the FSP provides the following advantages: (1) a solid-state process to avoid problems associated with liquid metallurgy; (2) severe plastic deformation to enhance mixing and refining of constituent phases in the material; and (3) hot consolidation to form fully dense solid. During this process, the material undergoes intense plastic deformation, which may result in significant homogenized nanoparticle distribution [6].

Materials used for tribological applications should be able to support a load without distortion, deformation or fracture and should have low wear combined with low

Available online at http://link.springer.com/journal/40195

M. Saadatmand · J. Aghazadeh Mohandesi ( $\square)$

Department of Mining and Metallurgical Engineering, Amir

Kabir University of Technology, Hafez Ave, Tehran, Iran

e-mail: agazad@yahoo.com friction coefficient under sliding contact [7]. The friction and wear behavior of the composites is known to be dependent on the microstructural characteristics of the matrix and also on the type, shape, size, and mass fraction of the reinforcing particles [7]. Compared to the micro-sized particle-reinforced metal matrix composites, the nano-sized particle-reinforced metal matrix composites possess superior strength, ductility, and wear resistance [8].

A high number of studies have been reported in literature regarding the tribological behavior of homogeneous metal matrix composites [9-11]; however, the information about the tribological response of these materials when prepared as functionally graded (FG) composite using FSP is scarce. In the previous work [12], we only compared the wear resistance of FG with homogeneous composite. According to our results, the FG composite showed better wear resistance than homogeneous composite. However, achievement of FG composite with optimized mechanical properties and wear characterization may be of research interest.

Therefore, the aim of present study is to investigate the effect of the mass fraction distribution on the mechanical properties and wear behavior to obtain a FG composite with the highest tensile strength and wear resistance. 


\section{Experimental Procedure}

Plate of aluminum 6061-T6 alloy with a size of $330 \mathrm{~mm} \times 50 \mathrm{~mm}$ and a thickness of $8 \mathrm{~mm}$ with chemical composition (in wt\%) of $0.54 \mathrm{Si}, 0.8 \mathrm{Mg}, 0.07 \mathrm{Mn}, 0.2 \mathrm{Cu}$, $0.4 \mathrm{Fe}$, and balance of $\mathrm{Al}$, and nano-sized $\mathrm{SiC}$ powders (purity is $99.5 \%$ and particle size is $50 \mathrm{~nm}$ ) were used as the base material and reinforcement particles, respectively.

The FSP tool material was made of $\mathrm{H} 13$ steel, with shoulder diameter of $20 \mathrm{~mm}$, threaded pin diameter of $7 \mathrm{~mm}$, and pin length of $5 \mathrm{~mm}$. The shape of pin is schematically indicated in Fig. 1a.

FSP was conducted using a vertical milling machine with tool rotating rate of $1,600 \mathrm{r} / \mathrm{min}$ and travel speed of $40 \mathrm{~mm} / \mathrm{min}$. The tool axis was tilted by $3^{\circ}$ with respect to the vertical axis of the plate surface. According to the previous work [13], to optimize the homogeneity of the particles inside the stir zone (SZ), above-mentioned condition was chosen. Then, $\mathrm{SiC}$ particles were compressed in a groove with depth of $5 \mathrm{~mm}$ in the middle of the specimens. In the beginning, a pinless tool was used to cover the top of the groove after filling with reinforcement $\mathrm{SiC}$ particles to prevent the particle scattering [14]. Consequently, the specimen was subjected to four FSP passes in order to improve homogeneity of particles.

In the present work, FG composites with surface $\mathrm{SiC}$ mass fraction of $2 \mathrm{wt} \%$ (named as $\mathrm{F}_{2}$ ), $5 \mathrm{wt} \%$ (named as $\mathrm{F}_{5}$ ), $8 \mathrm{wt} \%$ (named as $\mathrm{F}_{8}$ ), $10 \mathrm{wt} \%$ (named as $\mathrm{F}_{10}$ ), and $13 \%$ (named as $\mathrm{F}_{13}$ ) were fabricated. To produce the FG composite, $\mathrm{SiC}$ particles were packed into a groove with width of $1 \mathrm{~mm}$ (for $F_{2}$ ), $2 \mathrm{~mm}$ (for $F_{5}$ ), $3 \mathrm{~mm}$ (for $F_{8}$ ), $4 \mathrm{~mm}$ (for $F_{10}$ ) and $5 \mathrm{~mm}$ (for $F_{13}$ ) and depth of $5 \mathrm{~mm}$. As shown in Fig. 1a, the domed-like part of the pin produces the particle-reinforced layers with continuously graded architectures [15]. Also, the depth of produced FG composite is approximately same as pin depth (i.e., about $5 \mathrm{~mm}$ ). The typical appearance of friction stir processed Al6061 with SiC particles is shown in Fig. 1b. As shown in Fig. 1b, the groove is effectively closed subsequent to FSP. Defects, for example, voids and cracks are not monitored on the surface, the top surface has very smooth quality, and there are almost no prominences or depressions.

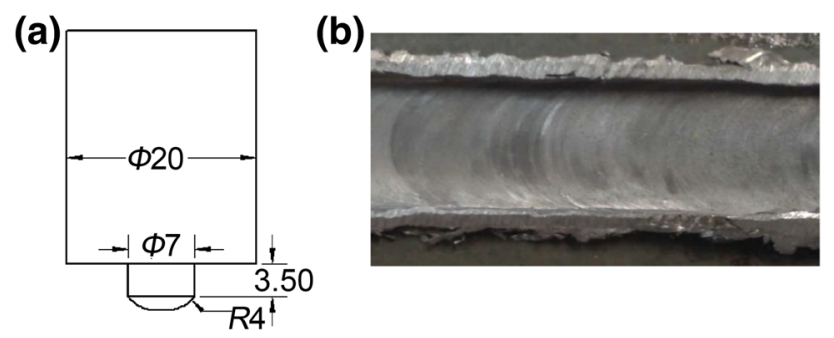

Fig. 1 a Dimension (unit: $\mathrm{mm}$ ) of the used pin for FSP; $\mathbf{b}$ appearance of FSPed Al6061 with $\mathrm{SiC}$ particles
Cross sections of FG composites were mounted and then mechanically polished and examined using a scanning electron microscope (SEM).

Energy-dispersive spectroscopy (EDS) line scan analysis of Si component was used for quantitative assessment of $\mathrm{SiC}$ particulate. Line scans were carried out on the midline of the cross section from the top to the bottom of the samples and averaged from three parallel lines separated by a distance of $0.5 \mathrm{~mm}$. The interval between the points on each line was about $350 \mu \mathrm{m}$. The microhardness profile was measured using Vickers microhardness tester at $1.0 \mathrm{~N}$ load and a dwell time of $10 \mathrm{~s}$.

Figure 2a shows the composite zone for $\mathrm{F}_{10}$ composite, in which the minimum composite zone width was observed for $F_{2}$ composite with width of $13 \mathrm{~mm}$. Tensile test of the specimens FSPed with $\mathrm{SiC}$ particles was determined in the room temperature via an Instron servo-hydraulic machine at a strain rate of $5 \times 10^{-3} \mathrm{~s}^{-1}$, in accordance with ASTM-E8 standard. Tensile test specimens were machined to the depth that FSP was applied, as Fig. 2b shown.

Wear experiments were conducted at room temperature under constant load of $20 \mathrm{~N}$ and a sliding velocity of $0.05 \mathrm{~m} / \mathrm{s}$, without lubrication. The counterpart pin was made of AISI GCr15 steel with a hardness value of about 60 HRC. The specimens were prepared by cut in $15 \mathrm{~mm} \times 15 \mathrm{~mm} \times 5 \mathrm{~mm}$ dimension from FG layer and were mounted, schematically shown in Fig. 3. Before the wear test, the surface of disk was ground by 1000 grit abrasive paper. Then, the disk was cleaned in acetone and weighed prior to testing. The experiments were stopped at the end of 500-m running, to measure the weight loss. Also, the morphological studies of the worn surface were made by scanning electron microscopy (SEM).
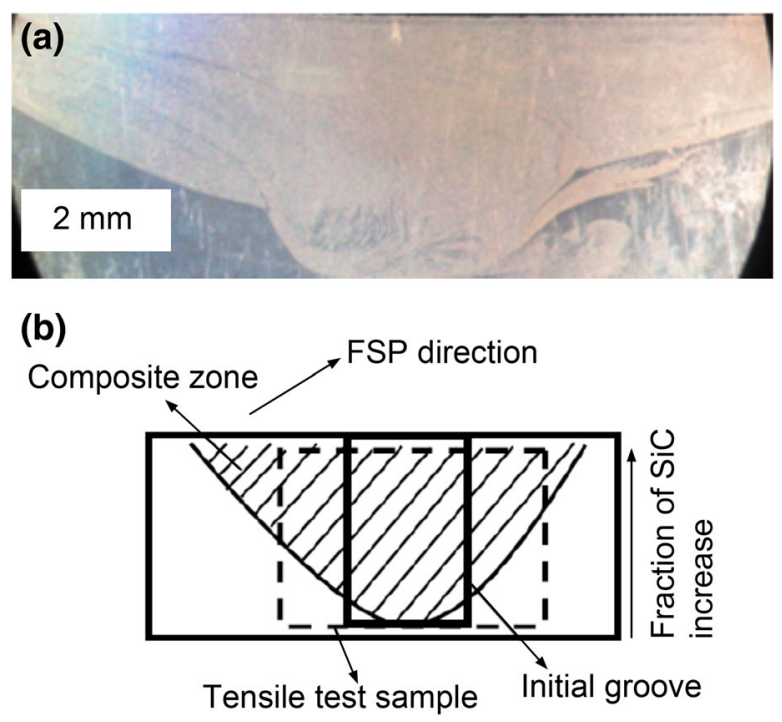

Fig. 2 a Photograph of the composite zone for $F_{10}$ composite; b Illustration of the position of tensile specimen 


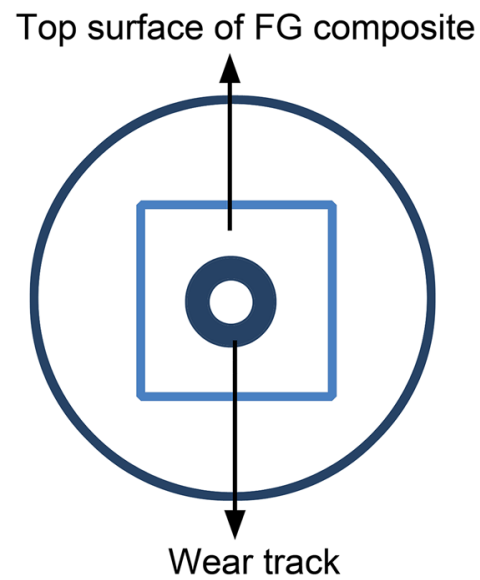

Fig. 3 Schematic illustration of wear test

\section{Results and Discussion}

\subsection{SiC Distribution}

Figure 4 indicates the profile of mass fraction of $\mathrm{SiC}$ as a function of distance from the surface for $F_{2}, F_{5}, F_{8}, F_{10}$, and $\mathrm{F}_{13}$ samples. Regarding obtained results, the mass fraction dispersion is about $\pm 7 \%$ of mean amount (the mentioned amount in the Fig. 4). Regarding Fig. 4, mass fraction of $\mathrm{SiC}$ on the surface is about $2,5,8,10$, and 13 wt $\%$ for $F_{2}, F_{5}, F_{8}, F_{10}$ and $F_{13}$, respectively, which continuously decreases with increasing distance from surface.

Figure 5 depicts the profile of microhardness as a function of distance from the surface for $\mathrm{F}_{2}, \mathrm{~F}_{5}, \mathrm{~F}_{8}, F_{10}$, and $F_{13-}$, respectively. Regarding obtained results, the mass fraction dispersion is about $\pm 7 \%$ of mean amount (the mentioned amount in the Fig. 5). Regarding Fig. 5, surface microhardness is about $62,73,87,103$, and $125 \mathrm{HV}$ for $\mathrm{F}_{2}$, $\mathrm{F}_{5}, \mathrm{~F}_{8}, \mathrm{~F}_{10}$, and $\mathrm{F}_{13}$, respectively, which continuously decreases with increasing distance from surface. The hardness value of the FSPed specimens with $\mathrm{SiC}$ powder is higher than that of the base metal. This is because of dispersion of the $\mathrm{SiC}$ particles as a harder phase, and severe grain refinement with respect to the base metal $[5,16]$. The observed increase in the hardness levels with increasing fraction of $\mathrm{SiC}$ is mainly due to Hall-Petch mechanism and particle strengthening effects which act as obstacles to the motion of dislocations.

\subsection{Microstructure}

Macroscopic appearances of nugget zone of $\mathrm{F}_{2}, \mathrm{~F}_{5}, \mathrm{~F}_{8}, \mathrm{~F}_{10}$, and $\mathrm{F}_{13}$ samples are shown in Fig. 6. As indicated in Fig. 6, some unmixed powders exist in $F_{13}$ sample. Regarding results reported by other researchers [5, 6], for high $\mathrm{SiC}$

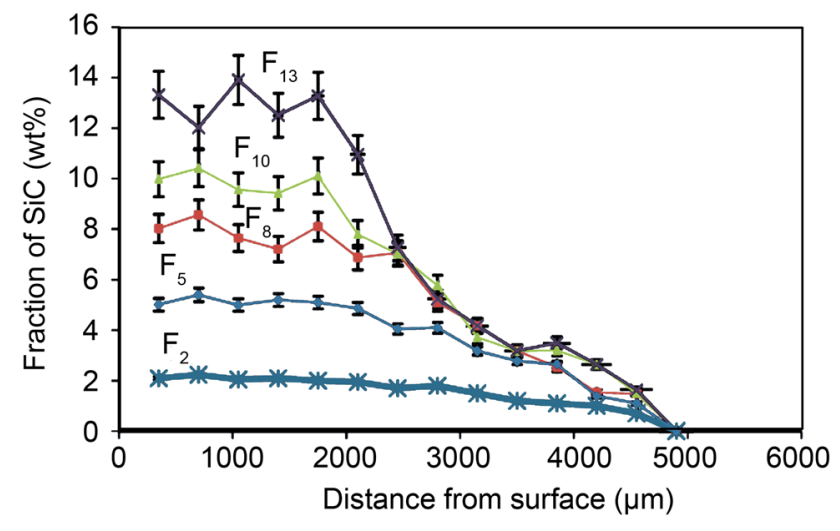

Fig. 4 Fraction of $\mathrm{SiC}$ as a function of distance from surface of FG composites

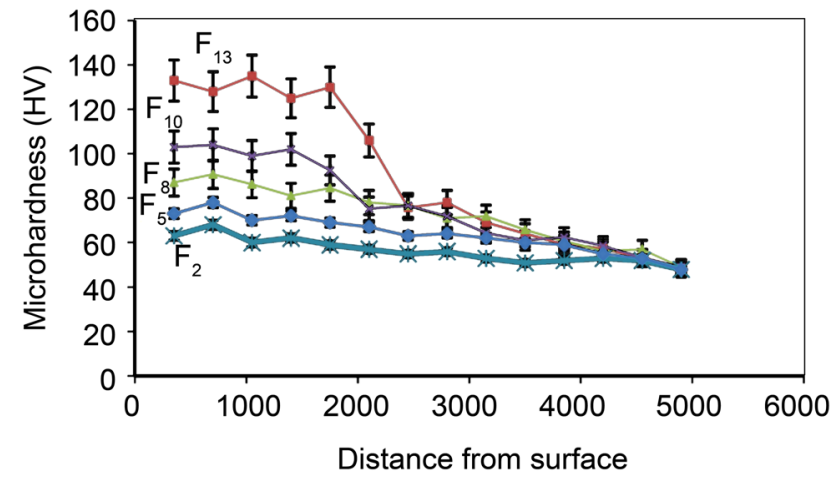

Fig. 5 Microhardness as a function of distance from surface of FG composites

fraction, due to the high probability of particle agglomeration, it is difficult to distribute them homogeneously using FSP.

The microstructure of $\mathrm{Al}-\mathrm{SiC}$ composites with different mass fraction distribution of $\mathrm{SiC}$ is shown in Fig. 7. As shown in Fig. 7, the reinforcement particles were uniformly distributed in $\mathrm{Al}-\mathrm{SiC}$ composites while they clustered in composite contained high mass fraction of reinforcement particles, i.e., $\mathrm{F}_{10}$ and $\mathrm{F}_{13}$ (marked as $A$ ), more severe for $\mathrm{F}_{13}$.

\subsection{Tensile Properties}

Figure 8 shows the stress-strain curve of FSPed specimens with different $\mathrm{SiC}$ particles mass fraction distributions. Step-like stress drop in the stress-strain diagram of FG composites is due to fracture of FG layers [17, 18]. Regarding Fig. 4, for initial $2 \mathrm{~mm}$ (approximately) the $\mathrm{SiC}$ mass fraction for three composites $\mathrm{F}_{8}, \mathrm{~F}_{10}$, and $\mathrm{F}_{13}$ is 8,10 and $13 \mathrm{wt} \%$, respectively. Stress drop occurs because at first the layer with high $\mathrm{SiC}$ mass fraction will fracture. Therefore, a drop in stress-strain curve will be observed. 

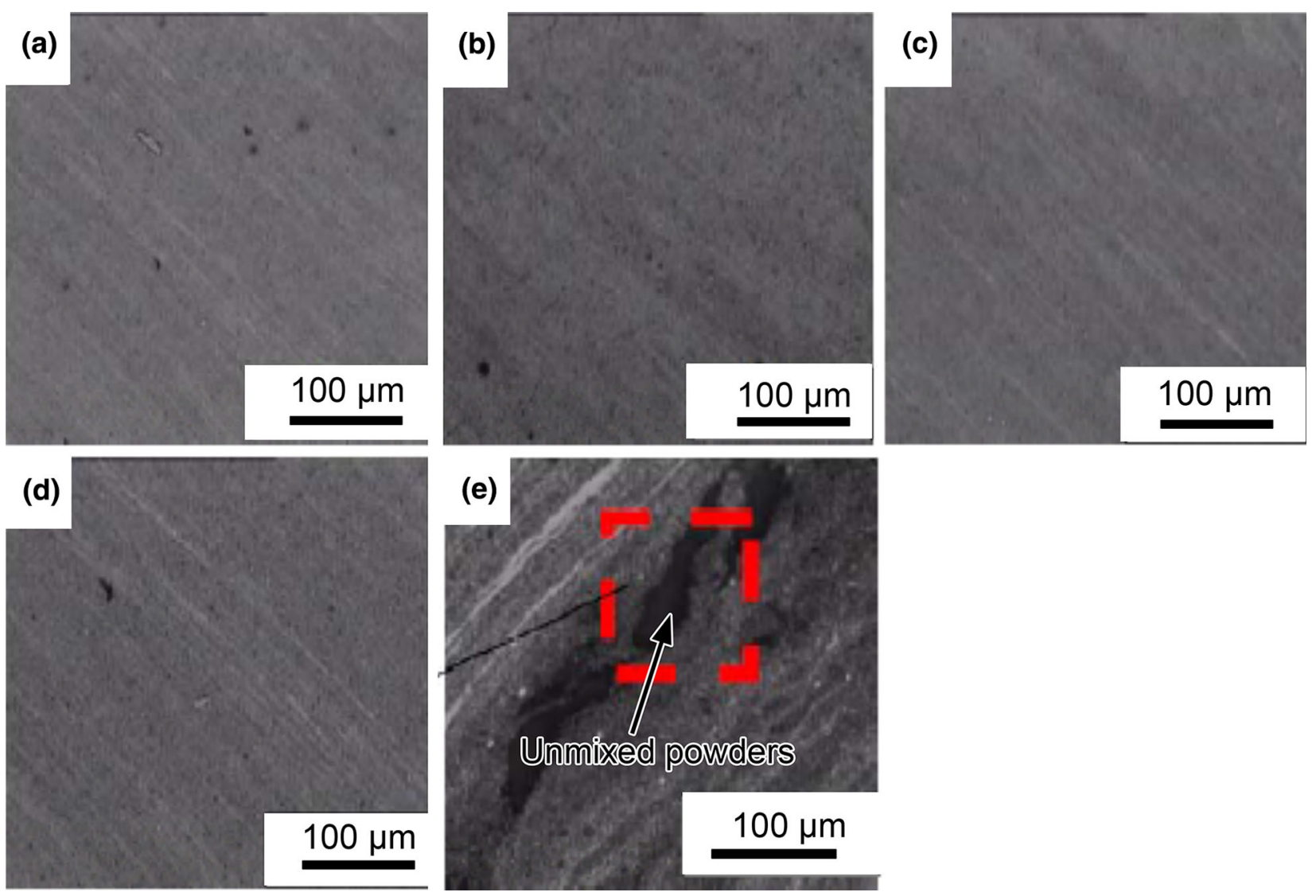

Fig. 6 Optical macroscopic appearances of cross section of $F_{2} \mathbf{a}, F_{5} \mathbf{b}, F_{8} \mathbf{c}, F_{10} \mathbf{d}, F_{13}$ e samples

But, because of FG interface, stress will decrease gradually after stress drop. The tensile properties depend on several microstructural factors, such as grain size, dislocation density, and interaction between the base metal and the reinforcing particles [5, 14]. From Fig. 8, it is clear that elongation of specimens increasing with surface mass fraction of $\mathrm{SiC}$ decreases. Dispersion of every $\mathrm{SiC}$ particles severely limits the movement of dislocations and decreases the ductility significantly, the reduction in area after fracture, from $4 \%$ for $F_{13}$ increased to $30 \%$ for $F_{2}$. Obviously, with increasing surface $\mathrm{SiC}$ fraction, ductility decreases.

Table 1 lists the variation of $0.2 \%$ yield strength and ultimate strength of the composites with different $\mathrm{SiC}$ fractions. Regarding results obtained by Veeresh Kumar et al. [19], Al6061-SiC composite produced using stir casting had lower mechanical properties than $F_{2}$ and $F_{5}$ produced in the present work. Against the present work, due to severe interaction between molten metal and reinforcement particles, the production of composite with higher $\mathrm{SiC}$ fraction (more than $6 \mathrm{wt} \%$ ) using stir casting was impossible. Also, the Al6061-SiC produced by powder metallurgy by Lee et al. [20], because of microporosity, had lower mechanical properties. However, FG Al6061$\mathrm{SiC}$ produced using roll bonding by Pouraliakbar et al. [21] had higher mechanical properties than produced FG composite in the present work. It could be due to severe plastic induced during roll bonding and tough bonding between layers of Al-SiC. For FG composite produced by stir casting [22], the mechanical properties were lower than those of $\mathrm{F}_{2}$ and $\mathrm{F}_{5}$.

At first, the yield and ultimate strength of the composite increase with increasing $\mathrm{SiC}$ content. The enhancement in tensile strength is partly due to the higher work hardening rate of the particle-containing materials. Moreover, uniform distribution of $\mathrm{SiC}$ particles affects the strength of the composites. However, according to the results of present research, the significant improvement in strength is achieved when surface $\mathrm{SiC}$ fraction is $10 \mathrm{wt} \%$ (i.e., $\mathrm{F}_{10}$ ). Further increase in $\mathrm{SiC}$ content leads to the reduction in yield and tensile strength. This could be the result of agglomeration of particles and higher degree of defects and microporosity present in the composite at higher $\mathrm{SiC}$ content. The results are consistent with the trends presented by other investigators [22]. It should be mentioned that $\mathrm{SiC}$ particles act as potent sites for nucleation of porosities so, with increasing $\mathrm{SiC}$ content, the microporosities increase which might lead to the lower flow stress in composite. On the other hand, increasing dislocations and other defects around $\mathrm{SiC}$ might result in debonding of the interface and decrease in ultimate tensile strength in the composites with 

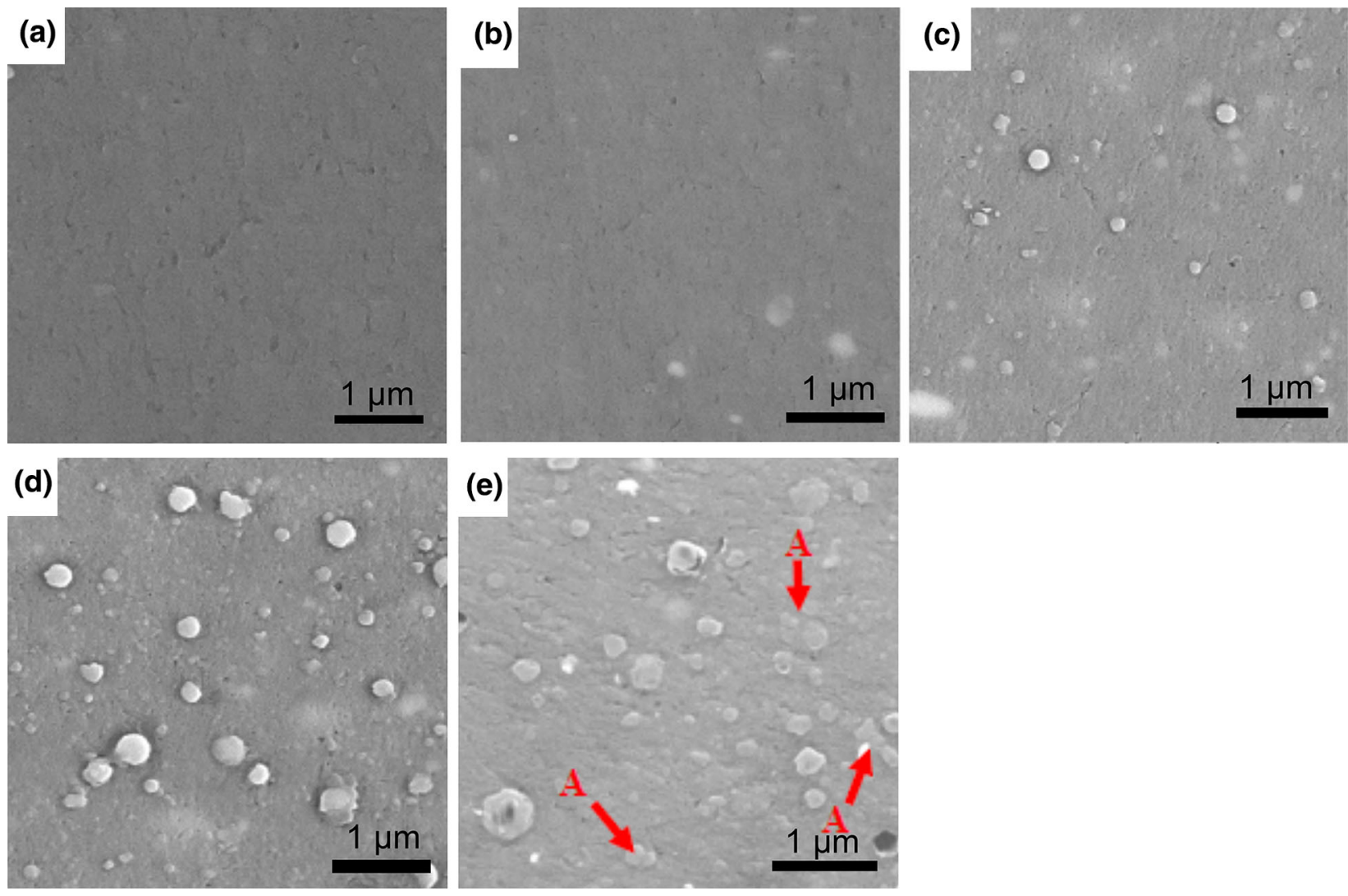

Fig. 7 Back-scattered SEM images of $F_{2} \mathbf{a}, F_{5} \mathbf{b}, F_{8} \mathbf{c}, F_{10}$ d, $F_{13}$ e samples, arrows $A$ in Fig. 7e showing clustering for $F_{13}$

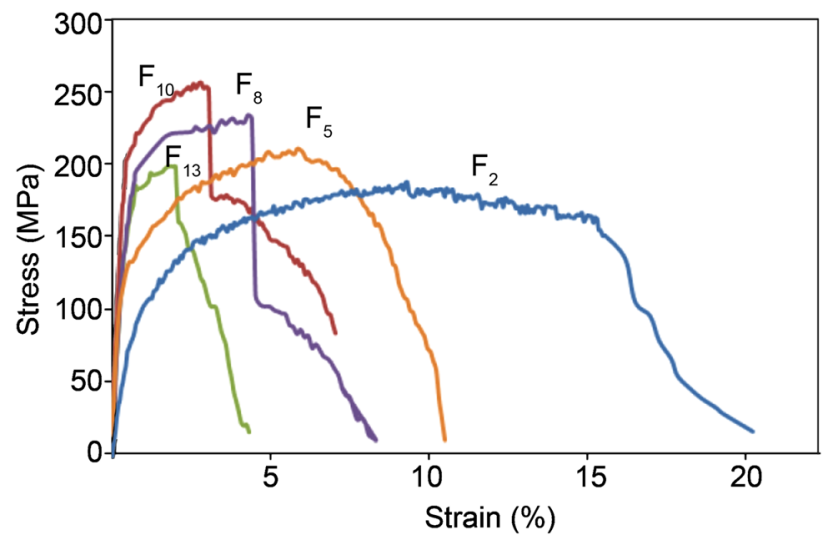

Fig. 8 Stress-strain curves of $\mathrm{F}_{2}, \mathrm{~F}_{5}, \mathrm{~F}_{8}, \mathrm{~F}_{10}$, and $\mathrm{F}_{13}$ samples

more $\mathrm{SiC}$ mass fraction. It should be noted that for FG composite produced by stir casting process [22], the decrease in mechanical properties occurred for lower mass fraction against FG composites produced by FSP in the present work.

\subsection{Wear Characterization}

Table 1 presents the effect of mass fraction distribution on the weight loss of $\mathrm{Al}-\mathrm{SiC}$ composites. As listed in Table 1,
Table 1 Mechanical properties and weight loss of $\mathrm{F}_{2}, \mathrm{~F}_{5}, \mathrm{~F}_{8}, \mathrm{~F}_{10}$, and $\mathrm{F}_{13}$ samples

\begin{tabular}{llll}
\hline Composite & $\begin{array}{l}0.2 \% \text { yield } \\
\text { strength }(\mathrm{MPa})\end{array}$ & $\begin{array}{l}\text { Ultimate } \\
\text { strength }(\mathrm{MPa})\end{array}$ & Weight loss $(\mathrm{g})$ \\
\hline $\mathrm{F}_{2}$ & 102 & 185.3 & $0.0092 \pm 0.0002$ \\
$\mathrm{~F}_{5}$ & 117 & 205.3 & $0.0060 \pm 0.0002$ \\
$\mathrm{~F}_{8}$ & 144 & 234.5 & $0.0041 \pm 0.0002$ \\
$\mathrm{~F}_{10}$ & 176 & 248 & $0.0025 \pm 0.0002$ \\
$\mathrm{~F}_{13}$ & 152 & 198.3 & $0.0032 \pm 0.0002$ \\
\hline
\end{tabular}

although wear loss decreased with increase in surface mass fraction, this trend significantly declined for $F_{13}$, because high-fraction $\mathrm{SiC}$ can negatively affect the mechanical behavior since particle clustering occurs as $\mathrm{SiC}$ fraction increases [23, 24]. This trend is in agreement with the results reported in other researches [25, 26].

Regarding results obtained by Veeresh Kumar et al. [19], Al6061-SiC composite produced using liquid metallurgy had higher wear resistance than produced $F_{2}$ and $F_{5}$ composite in this work. It could be due to higher hardness compared to $F_{2}$ and $F_{5}$. The Al6061-SiC produced by powder metallurgy by Lee et al. [20] had lower wear resistance. Because of microporosity, the reinforcement 

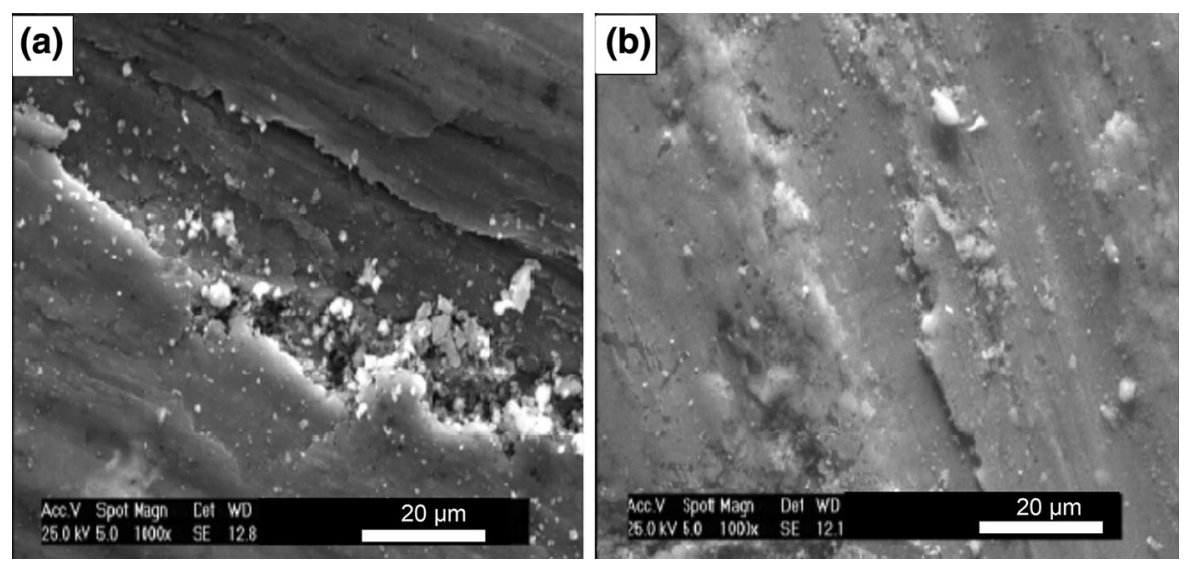

Fig. 9 SEM micrograph of worn surfaces of $F_{2}$ a, $F_{5}$ b samples

particles easily dislodged from surface, as a result, the wear process will accelerate.

The worn surface of $F_{2}$ and $F_{5}$ is shown in Fig. 9. As indicated in Fig. 9, the severe plastic deformation and material removal are the main mechanisms. Because of low amount of $\mathrm{SiC}$, the composite is relatively directly exposed to the cutting action of the counterface material which causes high rate of material removal. When the fraction of $\mathrm{SiC}$ particles increases, the increased content of particles helps the matrix to offer resistance to the cutting action. The protrusions from and irregularities of surface are subjected to tacking and cut down thereafter which is a symptom of adhesive wear occurring in that area [27].

Hard SiC particles with transfer iron from the counterface [28] and formation of a protective layer enhance the wear resistance of composite. The worn surface of $F_{8}$ was characterized by longitudinal grooves (marked as $A$ ) and some delamination and plastic deformation (marked as $B$ ) as shown in Fig. 10, but in comparison with the worn surface of $F_{2}$ and $F_{5}$, the degree of subsurface deformation and material removal decreased. However, it seems that layer formed on the worn surface of the $\mathrm{F}_{8}$ is inadequate to form a protective layer.

The lowest wear loss was achieved for the composite reinforced with $10 \mathrm{wt} \%$ surface $\mathrm{SiC}$ (i.e., $\mathrm{F}_{10}$ ). The reinforcement $\mathrm{SiC}$ particles act as load bearing components by improving the mechanical properties of composites with high $\mathrm{SiC}$ fractions [29]. Also, protruded reinforcement particles are effective in protecting the composite surface the asperities of counterface. As seen in Fig. 11, the wear mechanism of the composite with $10 \mathrm{wt} \%$ surface $\mathrm{SiC}$ is abrasive wear (marked as $A$ ) and plastic deformation (marked as $B$ ). In contrast to worn surface of $\mathrm{F}_{8}, \mathrm{~F}_{2}$, and $\mathrm{F}_{5}$, the degree of material removal is relatively disappeared. The worn surface appeared relatively smooth when the $\mathrm{SiC}$ fraction was $10 \mathrm{wt} \%$ [30]. This is due to the fact that the $\mathrm{SiC}$ reinforcements were protruded to the surface and thus protect the matrix alloy from further wear [31].

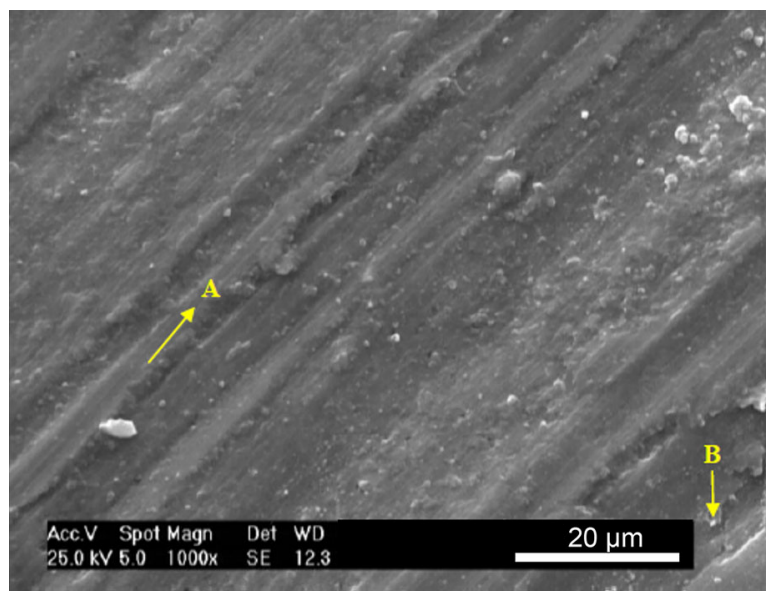

Fig. 10 SEM image of worn surface of $F_{8}$ sample

The weight loss increases for $\mathrm{F}_{13}$. It can be attributed to cluster formation of the reinforcement particles. Wang and Rack [32] explained that cluster regions act as an asperity on the wear surface of the composite. Moreover, as presented by Lin et al. [33], the reinforcement particles placed in cluster region have insufficient bonding to each other. Therefore, they are more easily dislodged from the cluster region at the initial stage of the wear process [34]. The pulling out (separation) of particles and wear process intensification as a result of its additional interaction with cutting surfaces has been observed in composite. In the course of time, the particle is crushed and removed out of the wear trace area. Additionally, it is possible that the reinforcing particle is indented into the matrix. Therefore, an adhesive tacking with composite matrix fragment occurs and consequently leads to its pulling out or to plastic deformation of matrix observed as "smearing over" of matrix on the friction surface, as confirmed by Walczak et al. [27]. In addition, once reinforcement particles on the composite surface are dislodged, they leave behind them some voids (marked as $A$ in Fig. 12). Also, the severe 


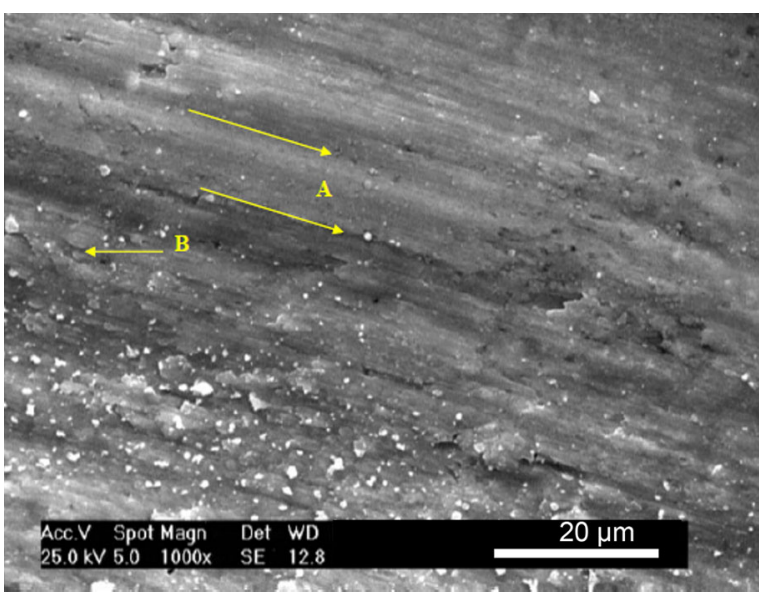

Fig. 11 SEM image of worn surface of $F_{10}$ sample

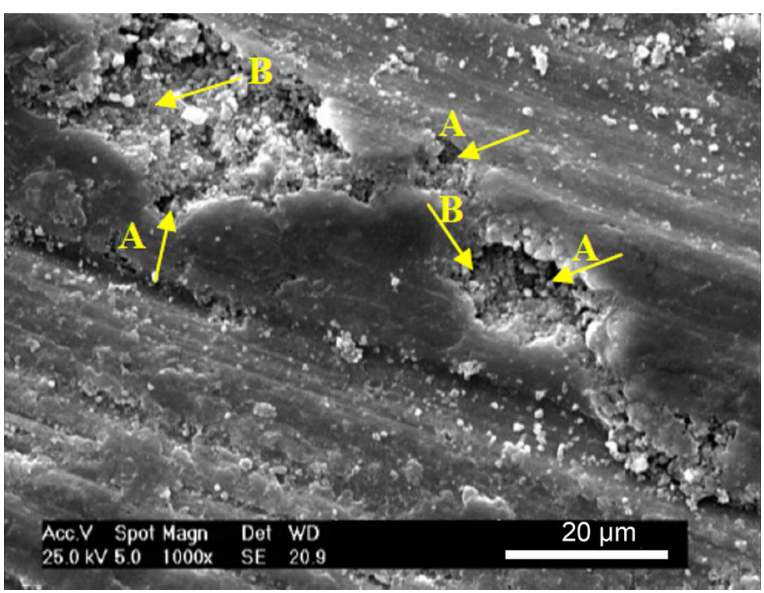

Fig. 12 SEM image of worn surface of $F_{13}$ sample

surface damage in the form of decohesion and detachments of the material are observed (marked as $B$ in Fig. 12).

\section{Conclusions}

FSP was successfully applied to produce $\mathrm{FG}$ Al-SiC composite. Regarding mechanical properties and wear characterization, the following results were achieved:

1. Compared to homogeneous composite, FG composite has higher work of fracture and wear resistance.

2. The strength and wear resistance of FG composite was dependent on the $\mathrm{SiC}$ fraction.

3. The optimized FG composite with the highest mechanical properties and wear resistance was achieved for sample with $10 \mathrm{wt} \%$ surface $\mathrm{SiC}$.

4. Particle clustering deteriorated mechanical properties and wear resistance of FG composite with high $\mathrm{SiC}$ surface mass fraction.

\section{References}

[1] I. Charit, R.S. Mishra, Acta Mater. 53, 4211 (2005)

[2] C. Lee, J.C. Huang, P. Hsieh, Scr. Mater. 54, 1415 (2006)

[3] D.K. Lim, T. Shibayanagi, A.P. Gerlich, Mater. Sci. Eng. A 507, 194 (2009)

[4] Y. Moruisad, H. Fujii, T. Nagaoka, K. Nogi, M. Fukusumi, Composites A 38, 2097 (2007)

[5] A. Shafiei-Zarghani, S.F. Kashani-Bozorg, A. Zarei-Hanzaki, Mater. Sci. Eng. A 500, 84 (2009)

[6] R.S. Mishra, M.W. Mahoney, S.X. McFadden, N.A. Mara, A.K. Mukherjee, Scr. Mater. 42, 163 (2000)

[7] J.R. Gomes, L.A. Rocha, S.J. Crnkovic, R.F. Silva, A.S. Miranda, Mater. Sci. Forum 423-425, 91 (2003)

[8] D.S. Zhou, F. Qiu, H.Y. Wang, Q.C. Jiang, Acta Metall. Sin. (Engl. Lett.) 27, 798 (2014)

[9] C.S. Ramesh, A.R.A. Khan, N. Ravikumar, P. Savanprabhu, Wear 259, 602 (2005)

[10] J. Hu, D.Y. Li, R. Llewellyn, Wear 259, 6 (2005)

[11] J.K.M. Kwok, S.C. Lim, Compos. Sci. Technol. 59, 55 (1999)

[12] M. Saadatmand, J.A. Mohandesi, J. Mater. Eng. Perform. 23, 736 (2014)

[13] M. Salehi, M. Saadatmand, J.A. Mohandesi, Trans. Nonferrous Met. Soc. China 22, 1055 (2012)

[14] R. Sathiskumar, N. Murugan, I. Dinaharan, S.J. Vijay, Mater. Charact. 84, 16 (2013)

[15] M. Salehi, H. Farnoush, J.A. Mohandesi, Mater. Des. 63, 419 (2014)

[16] P. Asadi, M.K. Besharati, Givi. Int. J. Adv. Manuf. Technol. 51, 247 (2010)

[17] L.L.M. Jr, Mishnaevsky. Compos. Sci. Technol. 66, 1873 (2006)

[18] S. Amada, S. Untao, Composites B 32, 451 (2001)

[19] G.B. Veeresh Kumar, C.S.P. Rao, N. Selvaraj, Composites B 43, 1185 (2012)

[20] H.L. Lee, W.H. Lu, S.L. Chan, Wear 159, 223 (1992)

[21] H. Pouraliakbar, R. Bagheri, S.M. SeyedReihani, Ceram. Int. 40, 8809 (2014)

[22] A. Mazahery, H. Abdizadeh, H.R. Baharvandi, Mater. Sci. Eng. A 518, 61 (2009)

[23] S.A. Sajjadi, M. Torabi Parizi, H.R. Ezatpour, A. Sedghi, J. Alloys Compd. 511, 226 (2011)

[24] E.A. Diler, R. Ipek, Mater. Sci. Eng. A 548, 43 (2012)

[25] S. Kumar, V. Balasubramanian, Wear 264, 1026 (2008)

[26] S. Suresha, B.K. Sridhara, Compos. Sci. Technol. 70, 1652 (2010)

[27] M. Walczak, D. Pieniak, M. Zwierzchowski, Arch. Civ. Mech. Eng. 15, 116 (2015)

[28] R.L. Deuis, C. Subramanian, J.M. Yellup, Compos. Sci. Technol. 57, 415 (1997)

[29] Y.Z. Zhan, G.D. Zhang, Y.H. Zhuang, Mater. Trans. 45, 2332 (2004)

[30] E.R.I. Mahmoud, M. Takahashi, T. Shibayanagi, K. Ikeuchi, Wear 268, 1111 (2010)

[31] A. Vencl, I. Bobic, B. Stojanovic, Ind. Lubr. Tribol. 66, 66 (2014)

[32] A. Wang, H.J. Rack, Acta Metall. Mater. 40, 2301 (1992)

[33] Y.C. Lin, H.C. Li, S.S. Liou, M.T. Shie, Mater. Sci. Eng. A 373, 363 (2004)

[34] P.N. Bindumadhavan, T.K. Chia, M. Chandrasekaran, H.K. Wah, L.N. Lam, O. Prabhakar, Mater. Sci. Eng. A 315, 217 (2001) 